First Peoples Child \& Family Review

An Interdisciplinary Journal Honouring the Voices, Perspectives, and Knowledges of

First Peoples through Research, Critical Analyses, Stories, Standpoints and Media

Reviews

\title{
Nog-da-win-da-min: A Collaborative Consultation with First Nations about Children's Well-being
}

\section{Heather Schmidt, Gayle Broad, Christine Sy and Rosalind Johnston}

Volume 7, Number 1, 2012

URI: https://id.erudit.org/iderudit/1068867ar

DOI: https://doi.org/10.7202/1068867ar

\section{See table of contents}

\section{Publisher(s)}

First Nations Child and Family Caring Society of Canada

\section{ISSN}

1708-489X (print)

2293-6610 (digital)

Explore this journal

Cite this article

Schmidt, H., Broad, G., Sy, C. \& Johnston, R. (2012). Nog-da-win-da-min: A

Collaborative Consultation with First Nations about Children's Well-being. First

Peoples Child \& Family Review, 7(1), 84-98. https://doi.org/10.7202/1068867ar
Article abstract

The history of the relationship between child welfare agencies in Canada and First Nations has been fraught with pain, and the removal of children from their families and communities is often described as an attempted cultural genocide. The realities of colonization, residential schools, and the "60s scoop" have created a legacy of pain and distrust which can be difficult for today's Native child welfare services to address. Nog-da-win-da-min Family and Community Services (NFCS) is an Anishinaabe agency that decided to consult with its seven member communities in order to obtain their input about future service development, but, with this legacy, were unsure how to engage the communities in meaningful dialogue. As such, they partnered with a team of researchers at NORDIK Institute to design and carry out a communitybased consultation. This article explores the collaborative process of creating and tailoring a consultation method to be an empowering and positive experience for participants, to be conducted within safe and accessible spaces throughout the communities. This required a thoughtful process development, which respected participants' knowledge and experiences (local knowledge), accommodated intergenerational trauma with sensitivity, and that employed Indigenous language and concepts (such as the Medicine Wheel) to guide the process. This article outlines some key learnings for others undertaking similar dialogues and consultations.
Copyright @ Heather Schmidt, Gayle Broad, Christine Sy, Rosalind Johnston, 2012
This document is protected by copyright law. Use of the services of Érudit (including reproduction) is subject to its terms and conditions, which can be viewed online.

https://apropos.erudit.org/en/users/policy-on-use/ 


\title{
First Peoples Child \& Family Review
}

An Interdisciplinary Journal Honoring the Voices, Perspectives and Knowledges of First Peoples through Research, Critical Analyses, Stories, Standpoints and Media Reviews

\section{Nog-da-win-da-min: A Collaborative Consultation with First Nations about Children's Well-being}

\author{
Heather Schmidta, Gayle Broad ${ }^{a}$, Christine Sy ${ }^{a}$, and Rosalind Johnston ${ }^{b}$

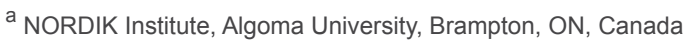 \\ ${ }^{\mathrm{b}}$ Nog-da-win-da-min Family and Community Services, Sault Ste. Marie, ON, Canada
}

\begin{abstract}
The history of the relationship between child welfare agencies in Canada and First Nations has been fraught with pain, and the removal of children from their families and communities is often described as an attempted cultural genocide. The realities of colonization, residential schools, and the "60s scoop" have created a legacy of pain and distrust which can be difficult for today's Native child welfare services to address. Nog-da-win-da-min Family and Community Services (NFCS) is an Anishinaabe agency that decided to consult with its seven member communities in order to obtain their input about future service development, but, with this legacy, were unsure how to engage the communities in meaningful dialogue. As such, they partnered with a team of researchers at NORDIK Institute to design and carry out a communitybased consultation. This article explores the collaborative process of creating and tailoring a consultation method to be an empowering and positive experience for participants, to be conducted within safe and accessible spaces throughout the communities. This required a thoughtful process development, which respected participants' knowledge and experiences (local knowledge), accommodated intergenerational trauma with sensitivity, and that employed Indigenous language and concepts (such as the Medicine Wheel) to guide the process. This article outlines some key learnings for others undertaking similar dialogues and consultations.
\end{abstract}

\section{Introduction}

Nog-da-win-da-min ${ }^{1}$ Family and Community Services (NFCS) is a Native child welfare prevention organization that provides services to the members of seven Anishinaabe First Nations located between Sault Ste. Marie and Sudbury, Ontario, and which together comprise the North Shore Tribal Council: Whitefish Lake, Sagamok Anishnawbek, Serpent River, Mississauga, Thessalon, Garden River and Batchewana. (Please see Map 1). The organization incorporated in August 1990 and is authorized as a Child and Family Services organization under Section 194 of the Province of Ontario's Child and Family Services

Corresponding author:

Heather Schmidt, Department of Psychology, Crape Breton University, Sydney, NS, B1P 6L2 heather_schmidt@cbu.ca
Act. It is mandated to develop partnerships and relationships related to providing child welfare services, and is responsible to its members for the provision of foster care, family preservation services, assisting families during Children's Aid Society investigations, and transferring

1 Nog-da-win-da-min is an Anishinaabe word meaning "Achieving a state of well-being by caring for each other." 


\section{First Peoples Child \& Family Review, Volume 7, Number 1, 2012}

Map 1: Location of the North Shore Tribal Council First Nations
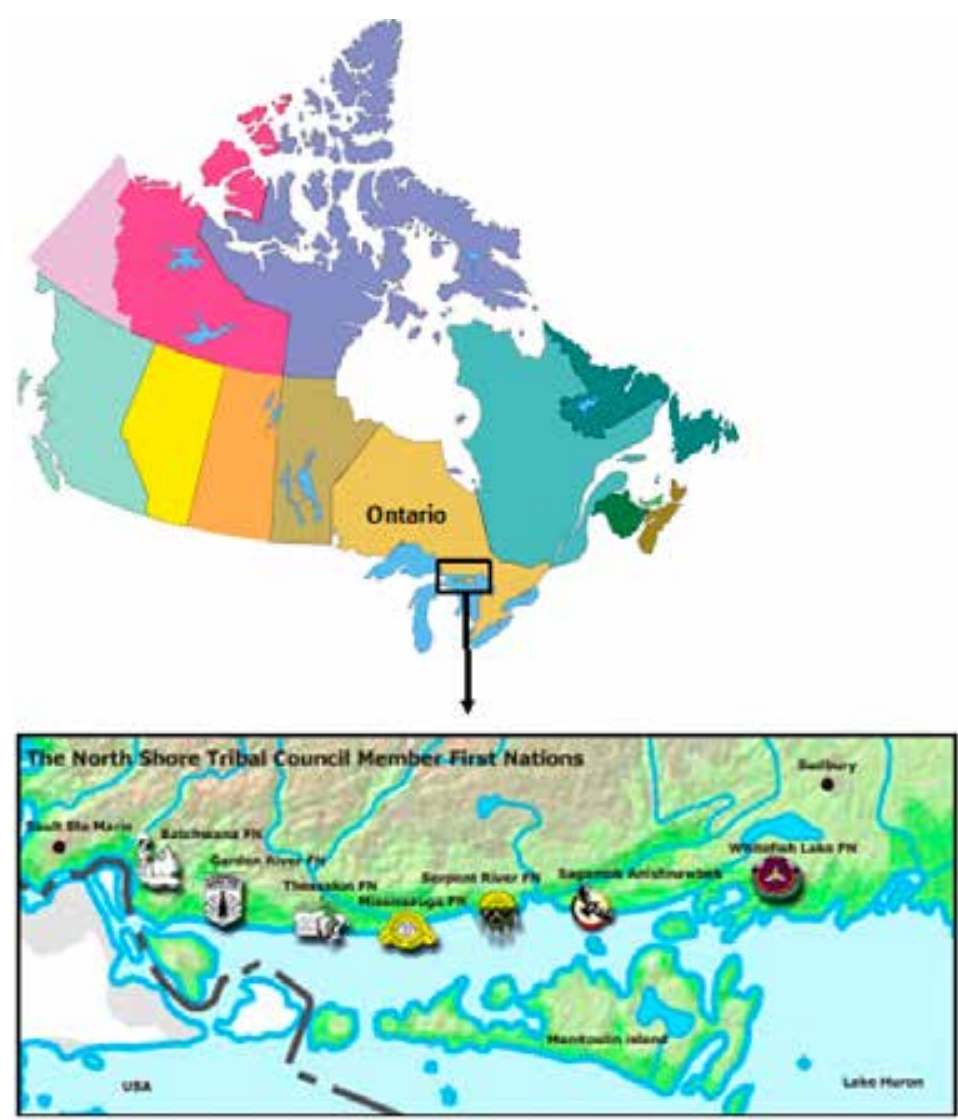

payments to member First Nations for delivery of community support services (i.e., primary child welfare prevention).

After 17 years of service provision, which included several changes in agency leadership and fluctuating priorities, the Nog-da-winda-min Board of Directors determined in 2007 that they needed to re-establish and improve their organization's relationship with the seven First Nations they serve. Specifically, they were interested in implementing a communitybased research project "to ensure that our community stakeholders . . . have relevant and timely child welfare information to determine the future direction of child welfare services for their communities" (Nog-da-win-da-min RFP document). How else would the organization know how to tailor its services to best meet community needs, without talking to a wide range of people within the communities? In February 2008, the NFCS organization contracted with NORDIK Institute (a community-based research institute at Algoma University) to partner with the Nog-da-winda-min board of directors and the seven communities in order to help them examine future directions for the organization in the provision of child welfare services. This article explores the process of engaging the communities in such a dialogue, and the lessons learned that may be of value to others.

\section{Engaging the Communities in a Dialogue about Child Welfare}

Engaging the community means taking ... a "to-do with" approach rather than a "to-do to" or "to-do for" [approach]. (Okubo \& Weidman, 2000, p. 309)

Engaging with First Nation communities in a dialogue about child welfare is a substantial challenge, given the disruption to traditional child-rearing methods caused by colonialism and the negative consequences for grief-stricken parents, disempowered communities, and traumatized children (Brubacher, 2006; Bennett \& Blackstock, 2002). Further, much of the literature about 
Acknowledgement: The authors of this report wish to acknowledge the support provided by the following people: Lorraine Naponse, Nog-da-win-da-min's Manager of Services, who provided guidance in all aspects of this community-based research consultation; the Board of Directors of Nog-da-win-da-min, who have had the courage and foresight to consult the communities they serve; with special thanks to board member Emma Meawasige for reminding us about the importance of acknowledging Anishinaabek ways of raising children in our process; Nog-da-win-da-min staff and First Nation staff who provided much logistical support to the project; And most sincerely, to each First Nation community —Whitefish Lake, Sagamok, Serpent River, Mississauga, Thessalon, Garden River and Batchewana-as well as to the Indian Friendship Center of Sault Ste. Marie; For every community member who willingly shared their time, knowledge and experience in these consultations - this could not be possible without you. Chi-miigwetch / thank you.

First Nations child-rearing has emphasized the deficits and dysfunctions of families in spite of the fact that this approach "tends to miss important elements of the client's life - cultural, social, political, ethnic, spiritual and economic" (Saleeby, 2002, p. 5, as cited in Boston \& Broad, 2007). A strengths-based "whole of community" healing approach is critical for working with Indigenous families (Libesman, 2004) because of the historical context of child welfare in Canada. As Chataway (1998) states, "A focus on strengths lends power to those strengths, and creates energy to produce more" (p. 18).

The literature on community engagement suggests that establishing respectful relationships by "starting where the people are" (Labonte \& Robertson, 1996, p. 441) is key, and that efforts at engagement must be culturally meaningful (Airhihenbuwa, 1995). Schnarch (2004) further emphasizes the importance of incorporating the OCAP principles (community-based Ownership, Control, Access, and Possession) into research endeavours with First Nations populations if one wishes to be ethical, and to help foster community-level healing and empowerment.

Nog-da-win-da-min had identified the questions to which they wanted answers, but not the methodological approach for asking the questions and eliciting community response. The approach needed to be free from bureaucratic/social-work jargon, yet meaningful and relevant from an Anishinaabe perspective. It needed to give community members from diverse backgrounds and educational levels sufficient information to enter into a discussion and form their own opinion, as well as to create the positive feelings, spirit of optimism and self-confidence for individuals to contribute to such a discussion. The agency could not simply call a meeting about "child welfare" and expect a diverse cross-section of people to willingly attend, nor could they merely sit people down and ask them to respond to a question such as, "Do you think Nog-da-win-da-min should become a fully-mandated child welfare agency?" It would have been disrespectful to enter the communities and ask such complex questions without first establishing a context.

Nog-da-win-da-min also expressed concerns that some community members might not feel comfortable providing candid critiques of the agency's services directly to its employees. Also, if the NFCS representative had strong personal opinions about the questions being asked, would they truly be open to hearing and understanding dissenting opinions? Smith (1999) and Mihesuah (1998) furthermore warn about the high level of distrust toward research that has been cultivated in First Nations by academics who, for decades, exploited Indigenous peoples for their own personal gain - acquiring degrees, grant money, awards, publications and professional esteem, while giving back little in return. The exploitative face of research in First Nation communities is aptly summarized in the following quote: 
First Peoples Child \& Family Review, Volume 7, Number 1, 2012

We know from past experiences that government research by white researchers never improved our lives. Usually white researchers spy on us, the things we do, how we do them, when we do them, and so on. After all these things are written in jargon, they go away and neither they nor their reports are ever seen again. (Nahanni, 1977, as cited in Jackson, 1993, p. 51)

As a matter of self-protection, many Indigenous people grew distrustful of research and today are no longer willing to be used as academia's "guinea pigs." Thus, considerable thought, planning, and reflection were needed to design a consultation methodology that would both meet the agency's needs and engage the communities in a highly respectful and collaborative manner (Ermine, Sinclair, \& Jeffrey, 2004). This article explores the process developed by Nogda-win-da-min and NORDIK, and the response of the communities involved.

Step 1: Pre-Consultation Considerations. Nog-da-win-da-min's board of directors identified a number of issues for consideration by NORDIK prior to commencement of the consultation process: a) Respect for community autonomy (i.e., each community must maintain control over any consultations conducted within its territory as outlined in the OCAP principles (Schnarch, 2004); b) Quantitative versus qualitative decision-making methods; c) Strategies for eliciting participation; and d) Ethical concerns, regarding the emotional safety of participants. Each of these concerns required different solutions:

a) Respect for Community Autonomy: Despite a shared Anishinaabe history and realities of colonization, resistance and revitalization, each of the seven First Nations had a unique history, culture, preferences, and needs. As such, it was recognized that each community needed to provide input about its own consultation process. Nog-da-win-da-min's executive director therefore contacted the seven communities and three urban off-reserve service providers (i.e., the Sault Ste. Marie Indian Friendship Centre, Wabinoong, and the Sault Ste. Marie office of the Métis Nation of Ontario) and requested some initial direction. In response, three communities and two of the urban off-reserve groups gave their approval to commence the consultation process, while the remaining four communities requested one or more pre-consultation meetings with the NORDIK researchers and an NFCS representative to discuss the proposed project. As a result, meetings were held with two Health \& Social Services committees, a Child Welfare committee, a general community meeting, a Health Director, and a First Nation administrative CEO. These initial sessions provided invaluable community input for the development and design of the methodology for the full consultation process, as will be described in more detail below.

b) Developing consensus about Qualitative vs. Quantitative Methods. Nog-da-win-da-min's intent from the conception of the project was to obtain rich, open-ended feedback in response to questions posed to the community. NORDIK proposed to obtain this through an extensive series of focus groups and interviews. According to Jackson (1993), qualitative methods tend to make intuitive sense to many Indigenous peoples because of their similarity to oral history traditions and because these research techniques involve a fairly straightforward and accessible process in which the interviewees have a lot of control over what they say to the researcher. An issue that emerged in the above community discussions, however, was whether or not it would be appropriate to supplement community feedback with quantitative data. In other words, would the research benefit from asking participants to formally vote on questions such as "Should Nog-da-win-da-min become a fully-mandated child protection agency?" Would it be advisable to develop a short yes/no survey which could be placed in community members' mailboxes, enabling a tabulation of the supporting versus dissenting percentages? 


\section{A collaborative consultation with First Nations about children's well-being}

While some were initially in favour of this additional component, others argued that interpretation of the results could pose a problem. For example, even if 45 per cent of survey participants voted in favour of Nog-da-win-da-min becoming fully mandated, there would be no way to determine why these people had voted in such a manner. Also, interview and focus group methods would allow for researchers to share some vital information with participants about Nog-da-win-da-min's current services, whereas survey participants would not necessarily have the same information and might not be fully aware of the ramifications of their choice. Furthermore, some community members might be undecided and unable to choose between a yes or no response option, or might have more complex responses, such as "Yes, I would support Nog-da-win-da-min becoming mandated but only if the following conditions can first be met...." After much discussion and debate, it was concluded that focus groups and interviews were the most appropriate methods because they would provide the richest feedback and allow participants the space to engage meaningfully with the questions being posed.

c) Participation Strategies. Being a neutral third party, it was decided that the NORDIK researchers would have the most likelihood of eliciting candid feedback from community members. At the pre-consultation meetings, NORDIK researchers asked the various committees for suggestions about eliciting participation within their communities. Given their insider knowledge about the communities, were there specific groups and/or individuals who should be invited to participate in the process? Were there any already-established group meeting times (among health and social services staff, Elders, parents, community kitchens, and so on) within the community that could potentially be visited for consultations? In three communities, NORDIK researchers were advised first to visit informally during regularly-scheduled Elders' lunches/teas to discuss the proposed focus group process, and then request permission from the Elders to return to conduct the consultation process at a later date. These initial meetings, though not part of the formal consultation process, allowed the researchers to become acquainted with individuals in the communities and to begin establishing the relationships and rapport which are so crucial for trust-building and acquiring candid responses.

During the pre-consultation phase, each community was asked to designate a "contact person" who would assist by organizing a series of two to four focus groups and inviting people to attend. At the meetings, it was also decided that the NFCS family preservation workers were the best people to assist in setting up interviews with former Nog-da-win-da-min clients. To further facilitate participation, the Nog-da-win-da-min agency covered the costs of snacks for each focus group, as well as the chance for each participant to put their name into a prize draw. Each of the seven communities, plus the urban off-reserve group, was given a donated prize and winners were selected at a general NFCS meeting held in September 2008.

d) Emotional Safety and related Ethical Concerns. Issues of emotional (and spiritual) safety for participants (as they relate to the history of child welfare within First Nations) were of key concern. One Elder on Nog-da-win-da-min's board of directors stressed the importance of finding ways to acknowledge Anishinaabek child-rearing practices in the consultation process. The various committees and NFCS staff also advised that a list of local support services (with contact information) should be included on NORDIK's consent forms, including local mental health professionals and community Elders who were willing to offer support and assistance. Each community was also asked whether they would like an Elder to be present during their focus groups and/or interviews. Depending on the needs of the particular community, the Elders were invited to say an opening and closing prayer (e.g., Anishinaabek or Christian), offer a smudging ceremony to begin the process, and be on hand to offer support to participants as needed. These 
Figure 1: Nog-da-win-da-min, Anishinaabek Children \& Minobimaadziwin

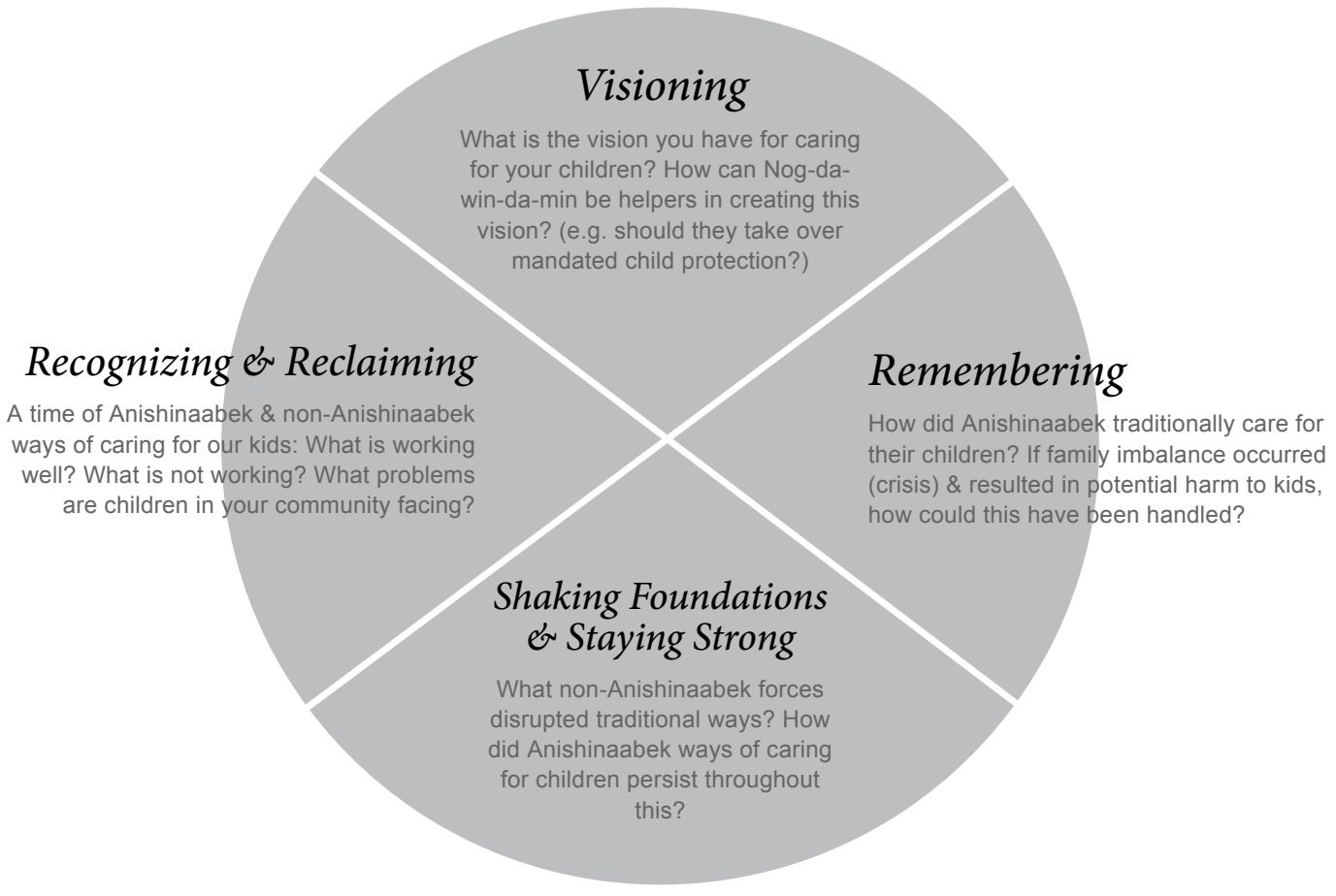

Elders also contributed their voices to the consultation process. To facilitate this support, Nogda-win-da-min offered an honorarium to each Elder as a way to recognize and honour their knowledge of ceremony, prayer, and participation. Reflecting the diversity among the seven First Nations, some focus groups requested and arranged for an Elder's assistance, while others did not deem it necessary.

Following these pre-consultation sessions, Nog-da-win-da-min's executive director obtained official permission from each of the communities' chief and council for NORDIK to commence conducting the focus groups and interviews that the various committees had agreed upon.

Step 2: Consultation Process. Based on a literature review (e.g., Gaikezheyongai's (2002) indepth discussion of medicine wheels), feedback from the NFCS board of directors, the preconsultation community meetings, and the insights of the researchers, NORDIK adapted a four-part medicine-wheel model (see Figure 1) to use in structuring the child welfare dialogue with the communities. A high priority was placed on using language, visuals, and other Anishinaabek-appropriate methods that would (a) be easily understood and accessible to a wide range of community members; and (b) function to create a space for empowered participation. Due to the complex nature of the subject matter for many people, this was a crucial component and also addressed the fact that not everyone entering into the dialogue possessed a working understanding of the current child welfare system.

a) Language. Rather than utilizing the institutionalized language of "child welfare," NORDIK introduced the dialogue to community members by referencing the Anishinaabek concept 


\section{A collaborative consultation with First Nations about children's well-being}

of minobimaadziwin which translates as "living a good life". . Operating from this concept, participants were asked to consider the central question: "How do we help our children to live a good life?" The concept of shkaabewis or naadimaagejik (i.e., "helpers") was also discussed: researchers proposed that the Nog-da-win-da-min agency is currently one of the many different helpers that are available, when needed, to assist Anishinaabek families in helping their children to live a good life. In response, some groups shared different Anishinaabek words for helper. Interestingly, the word shkaabewis was not generally recognized by participants, whereas the word naadimaagejik was perceived to be more reflective of how the idea of "helper" is articulated in this region.

The meaning of the word nogdawindamin was also discussed with participants (i.e., "achieving a state of well-being by taking care of each other"). This translation was presented to participants to further enhance the Anishinaabek meaningfulness of the consultation process and to reflect the Anishinaabek roots of the Nog-da-win-da-min organization. Interestingly, though, two different Elders groups suggested that their understanding of the word nogdawindamin was "the process of thinking through a decision and weighing the options." Time and time again, Elders shared with us the importance of recognizing that the communities that comprise the North Shore Tribal Council, while similar in many regards, are also unique, and that one way in which this distinctiveness is revealed is in the different dialects that are spoken across the communities.

After reviewing and discussing these concepts with participants, the rationale for initiating the consultation process across all communities was explained (i.e., to assist the Nog-da-win-damin board in creating their new strategic plan), and then consent forms were distributed to the participants. After answering all questions and obtaining permission to make an audio-recording of the sessions, the more formal part of the consultation process began.

b) The Medicine Wheel. In each of the community focus groups and interviews, the visual image in Figure 1 was presented and then used to guide the discussion and elicit feedback from the participants on four major topics:

East/Past - Anishinaabek child-rearing practices prior to the arrival of Europeans and European influences ("What would have happened if one parent died and the other was unable to care for the children?" was a sample prompt);

South/Past - Disruptions to Anishinaabek child-rearing practices that occurred as a result of European and Euro-Canadian colonialist practices, as well as methods of resistance and cultural persistence employed by the Anishinaabek (e.g., finding covert ways to continue passing on spiritual practices, hiding children from Indian Agents, and so on);

West/Present - Reclaiming and recognizing both the strengths and areas for improvement in the current child care system as they pertain to Anishinaabek children and families. In order to facilitate this discussion, the researchers presented a second diagram that depicts a visual overview of the current system of programs and services for families and children, including an overview of Nog-da-win-da-min's services (See Figure 2);

North/Future - Visions (i.e., hopes, dreams, wishes) of community-level caring for children and how, specifically, the Nog-da-win-da-min organization should ideally help in creating this vision. A final question then posed to participants was: "Do you want Nog-da-win-da-min to

2 All Anishinaabe terms and definitions were provided by researcher Christine Sy, with additional input provided by community members. 


\section{First Peoples Child \& Family Review, Volume 7, Number 1, 2012}

Figure 2: West - A brief overview of the present system of programs and services for families and children

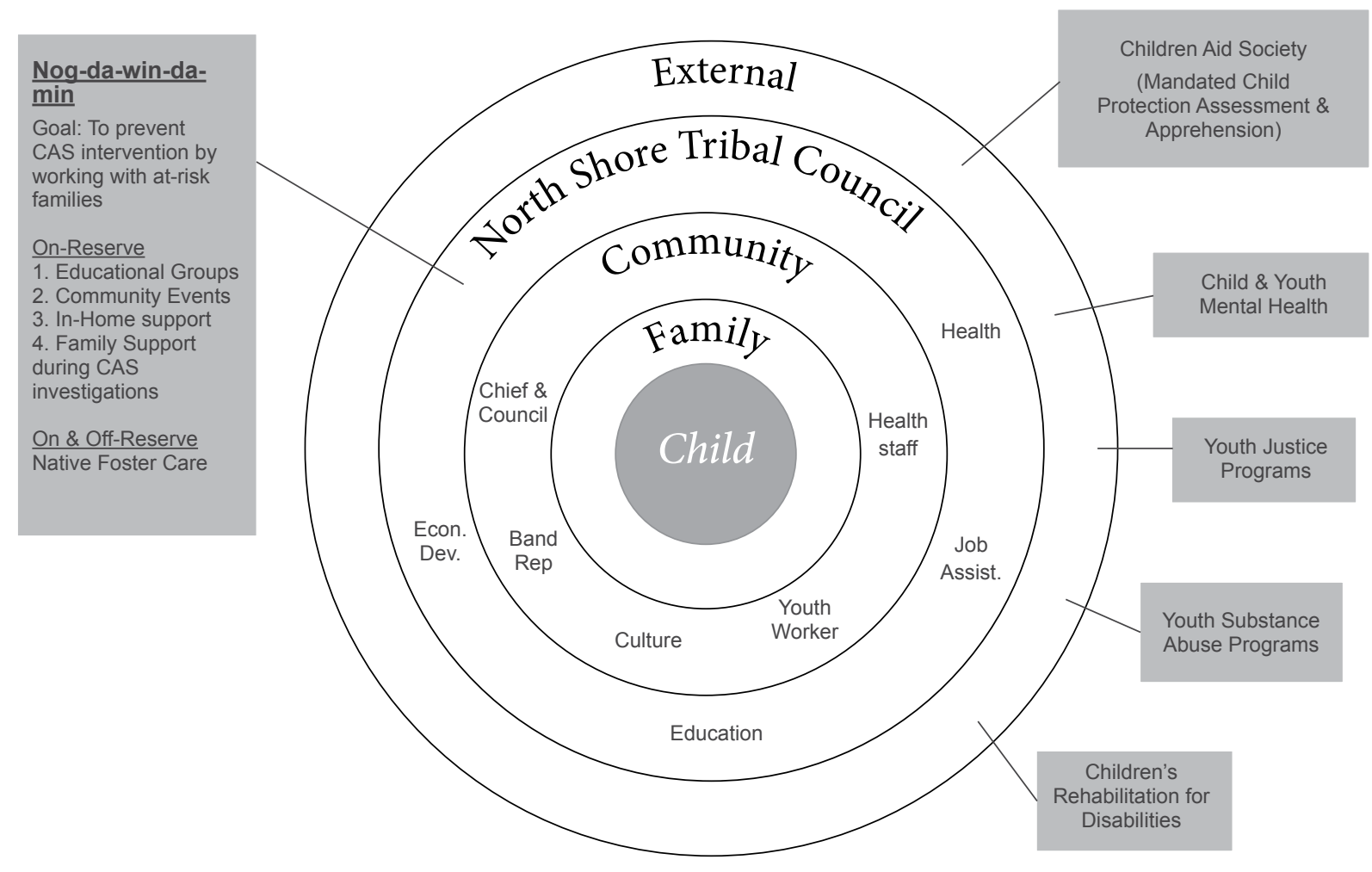

expand its current program delivery to include child protection services?" Exploration of pros and cons was encouraged.

This framework proved highly beneficial and was a crucial foundation in the consultation process. It facilitated meaningful dialogue and provided information to the communities about Nog-da-win-da-min's current services, while at the same time eliciting a wide range of knowledge from the participants about the well-being of families and care of children in their communities. Participants also discussed concerns that they felt were most relevant for their families and communities. This provided a rich dialogue to inform Nog-da-win-da-min's future directions, as well as many possibilities, suggestions, and ideas for the participants' own communities in terms of how children can be cared for at the community level.

c) Response from the Communities. The consultation took the form of 21 focus groups and eight interviews, which were held in all seven First Nation communities serviced by Nog-dawin-da-min, as well as with NFCS staff members and an urban off-reserve group at the Indian Friendship Centre in Sault Ste. Marie. During the initial consultation process, the communities had recommended that NORDIK should consult with Elders groups, health and social services staff, general community meetings, and former Nog-da-win-da-min clients, and these recommendations were carried out. The number of sessions in each community varied as a result 


\section{A collaborative consultation with First Nations about children's well-being}

of both community preferences and availability, as did the number of participants (ranging from a minimum of two people per focus group to a maximum of 12 people per group). In total, 146 individuals participated in the consultation process.

Step 3: Interim Community Feedback Sessions. Following the consultations, NORDIK researchers created nine separate draft reports to summarize the different themes that emerged in each of the participating communities (for seven First Nations, one urban centre group, and one Nog-da-win-da-min staff group). The researchers then revisited each of the communities to present these reports and ask the questions: "Is your perspective accurately reflected in this document? Is there anything missing?" - thus ensuring accuracy of the data analysis. This process provided an opportunity for the researchers to further clarify some of the points raised, as well as to discuss the initial consultation process with the communities retrospectively. Furthermore, it provided a second opportunity for reflection upon the consultation questions by the community itself. These second groups often contained some individuals who had been unable to participate in the initial consultation sessions, and so this expanded somewhat the initial participation numbers as well as the variety of perspectives represented in the draft reports. In total, 75 individuals participated in the feedback sessions.

Some communities requested additional time to distribute and discuss their draft summaries and so extra copies of the reports were provided to facilitate this. Additional community feedback was emailed to the NORDIK researchers following these short review periods. After receiving community feedback, the researchers revised the summaries and then emailed them back to the community contact people for general community distribution and sharing. To respect each community's ownership and confidentiality of their own data, the only community-level interim report that was provided to Nog-da-win-da-min was the one which summarized the themes emerging from the sessions conducted with agency staff members. It was hoped that the stories, ideas, and findings will prove interesting and useful to all community members - individuals, families, groups, service providers, political leaders - in their ongoing efforts to support and nurture the children of their communities. ${ }^{3}$

Step 4: Assessing the Validity of Research Findings. During discussions between the NORDIK researchers, Nog-da-win-da-min leadership and others, some concerns and questions about research validity were raised with regard to the number of participants involved in the consultation. Some people wanted to know (a) why the participation numbers weren't higher, and (b) if this posed a problem for the research findings and conclusions. Others wanted to know why the researchers had not set a quota of participants to ensure that a certain minimum percentage of known North Shore community members were recruited to participate in the research. Given that approximately 4,500 registered First Nation citizens live in the communities (reserves) across the seven North Shore First Nations and that about 2,200 of these members are adults, the question was raised as to whether 146 people (less than 10 per cent) could reliably speak on behalf of the total population. Could the research findings be viewed as a valid and accurate representation of the range of perceptions to be found across all seven communities and the urban membership?

A number of interesting perspectives and issues emerged in this discussion. In order to capture the complexity, NORDIK's approach was to: a) relay some thoughts that were shared by the Nog-

3 These findings will not be shared in this article. The Nog-da-win-da-min board of directors agreed to publish this article about the research process, but is still deciding whether the study results should remain public or private. Please feel free to contact the Nogda-win-da-min agency if you wish to learn more about them: www.nog.ca. 
da-win-da-min board of directors during a discussion with the NORDIK research team; b) present an academic qualitative research methods perspective on validity and sampling; and c) provide some insight into the challenges of eliciting community participation.

a) Nog-da-win-da-min and NORDIK dialogue about validity. On January 27, 2009, the NORDIK team presented the overall findings (summarized across all participating communities) from this study to the Nog-da-win-da-min executive director and board members. One board member initially expressed some concern regarding the low participation numbers (in relation to the total population across the seven communities), but she also indicated that when looking at the turn-out from her particular community, she was surprised and happy to see "that many" had come out to participate. This idea was confirmed by another person on the board who indicated that, because of the subject matter (i.e., child protection services, child abuse, CAS, etc.), she understood why people were reluctant to participate and that, indeed, this rate of participation was indicative of something quite positive: that some members of each community are ready and willing to begin talking, healing, and engaging actively in community restoration.

Indeed, in spite of some trepidation at the outset, participants frequently left the focus groups having found the consultation process a safe, surprisingly enjoyable, and stimulating experience. Laughing and joking frequently occurred within the groups as individuals shared stories, pooled knowledge, discussed the issues at hand, and enjoyed being together. Some groups became quite animated when discussing the complexities around the question, "Do you think Nog-da-win-damin should apply for CAS status and become a child protection agency?" People bounced ideas off each other and in some cases even began prompting and "interviewing" each other. Many people seemed simply to appreciate the fact that an agency was asking them for their opinions and really listening to what they had to say. A number of people asked the researchers if/when we were coming back to continue the discussion, and many indicated on their consent forms that they would like to receive a final copy of this research report. Given that two to three groups within each community were willing to come out and engage in such a discussion, it is quite likely that if Nog-da-win-da-min were to continue having these conversations every six months or so, momentum would build and more and more people would come out to participate. Thus, from this perspective, the level of participation was quite successful.

b) A Qualitative Research Methods Perspective. Objectives differ between quantitative and qualitative approaches to research. The priority with quantitative statistical research is to collect feedback from as many people as possible (Kirby, Greaves \& Reid, 2006). Conventionally, more participant contributions (i.e., bigger samples) are seen as better because they are more representative of the actual population. Although an advantage of numerical data is that large amounts can be amassed quickly, a limitation is that only fairly simplistic types of information can be tabulated. Statistical findings can be reported but the explanation as to why a certain percentage of people answered in a particular way can only be speculated on.

In contrast, the goal with qualitative research is to explore a topic in depth so that rich and complex understanding emerges (Mayan, 2009; Kirby, Greaves \& Reid, 2006). By necessity, asking exploratory, open-ended questions of people is a much more time-consuming approach. The central goal is not to achieve extremely high participation numbers but, instead, to ensure that the topic is explored as thoroughly as possible. Sampling techniques ensure that a diversity of perspectives has been included (Mayan, 2009). Furthermore, it is recommended that qualitative researchers continue collecting new information until "the saturation point" is reached, which refers to the point at which the researchers begin to hear a lot of repetition in the central themes 


\section{A collaborative consultation with First Nations about children's well-being}

being discussed (Shank, 2002). The researchers continue interviewing new participants until they reach the "saturation point" and can anticipate with a good degree of accuracy the topics that new participants will discuss in response to the consultation questions. Another test of validity in the qualitative approach is whether or not the findings resonate with readers, and provide them with new and useful sources of information and ideas (Mayan, 2009).

In the current study, NORDIK attempted to solicit a diversity of perspectives on the topic of child welfare by ensuring that the researchers held sessions within each of the seven First Nation communities, in addition to meeting with Nog-da-win-da-min staff and the urban Aboriginal community. Researchers made multiple visits to the different communities, and attempted to schedule visits on days and times that were convenient to community members. We also spoke to a wide variety of people within each community, such as Elders, community wellness staff, foster parents, former Nog-da-win-da-min clients, and community members in general. Two chiefs, some council members, a few band representatives (a legal position), and some of the original founding members of Nog-da-win-da-min also participated. NORDIK spoke to people who were supporters of Nog-da-win-da-min, people who were unfamiliar with the organization's services, and people who were critical of the organization.

Beyond ensuring a diversity of perspectives, we also reached a point after several months of soliciting people's thoughts, stories, and opinions, at which we were able to discern many common themes across the communities; thus, the saturation point criterion was achieved. Rather than continuing to collect data in order to boast higher participation numbers, it was more useful to Nog-da-win-da-min and to the communities to provide timely and accurate research findings, as soon as they became available.

When the final report was shared with the Nog-da-win-da-min board members and executive director, they validated the findings further when they commented that reading through the results had made them "laugh and cry," "gave them plenty of food for thought," and made them feel as though they "could hear the actual voices of community members speaking." As community members themselves, the board of directors and executive director indicated that the results resonated with them and that, in their opinion, the researchers had been successful in capturing the wide range of perspectives to be found across the different communities.

c) Some Challenges of Eliciting Participation. NORDIK aimed to be flexible and responsive to the "rhythm" of each community; however, overall community readiness to participate in a research project of this nature also affected participation rates. Some communities were quick to mobilize staff members and other resources to facilitate the consultation process. Staff members printed out posters advertising the sessions, personally invited community members to attend, coordinated the sessions around existing activities, and/or organized special lunch/dinner meetings. On the other hand, a variety of challenges to participation were encountered in some of the other communities:

i) The consultations took place primarily during the months of June, July, and August, and NORDIK was informed in advance that perhaps there would be a lower turnout during summer months for such reasons as summer holidays and the powwow season. Although NORDIK did accommodate some groups in September and October, it is possible that greater numbers might have been obtained at different times of the year. Summer scheduling appeared to pose special challenges for many (but not all) staff groups in terms of their rotating vacation schedules and trying to find time to accommodate the consultation process; 
ii) Two communities underwent elections of chief and council, and the newly elected councils required time to review the previous decision regarding the consultation process. Elections also sometimes meant that the community contact person changed (as First Nation employee roles changed) and thus the new individuals needed to be oriented to the project. Such people were facing the challenge of commencing a new job in addition to accommodating the needs of this project;

iii) On some occasions, the researchers arrived for scheduled focus groups and interviews only to have no one show up, or to find a very low turnout. NORDIK can only speculate as to the possible reasons, but some likely explanations may relate to the sensitive nature of the subject matter and/or difficulties in advertising and promoting the sessions. At other times, long relays of telephone messages were needed in order to contact suggested interviewees. Many people who were difficult to connect with led busy lives (e.g., taking care of children and/or grandchildren, working in seasonal businesses and/or holding down high-stress jobs). Sometimes scheduling a meeting time in advance was not possible due to their changing, hectic lives. In addition, many of the NFCS workers, who were helping NORDIK organize and advertise these community gatherings and interviews also had busy work schedules and family lives.

iv) On occasion, scheduling was complicated due to lingering distrust for the Nog-da-winda-min agency that was felt by some individuals, which resulted in a reluctance to participate in the research. In one community, for example, the consultation process was halted temporarily after some community members questioned whether their council had officially approved the consultation project and demanded to see written documentation ascertaining their approval. Scheduling was put on hold until such a letter was secured.

v) The consultation process was halted at another point to address concerns raised by Nog-dawin-da-min leadership regarding the consultation process. This resulted in the cancellation of a number of focus groups that had already been assigned dates, and may have contributed to lower participation rates in those communities affected by cancellations and rescheduling challenges.

In spite of challenges with distrust, uncertainty, and scheduling, however, it is positive to note that meetings were held with all concerned parties that subsequently resolved these issues and allowed the research consultation to progress to completion as planned.

\section{Conclusions: Why did this consultation approach work?}

a) Pre-Consultation Phase: The sessions enabled appointed members from the various communities to ask questions, make suggestions, raise concerns, and generally collaborate with the researchers in the development of the research tools. The methods were gradually tailored over the course of these meetings to better meet the needs of the different communities as well as those of Nog-da-win-da-min. While this process of gaining community-level approval and informed consent took two to three months longer to complete than was originally anticipated, it was nevertheless important because it ensured that the project followed appropriate ethical guidelines for conducting research within First Nations as outlined in the OCAP (Ownership, Control, Access, and Possession) principles (Schnarch, 2004). Furthermore, this step ensured that we respected the wishes of the communities as they expressed them, and, at the same time, it maximized our potential for collecting rich community feedback.

b) Holding a Test Group with Staff: Prior to conducting focus groups and interviews within the communities, NORDIK researchers ran through a series of focus groups with Nog-da-win-da- 


\section{A collaborative consultation with First Nations about children's well-being}

min staff. This was done to ensure that the wording, questions and process would be meaningful and comprehensible to community members and therefore solicit the desired information. This step also helped to better prepare NORDIK researchers for entry into the communities, and enabled the staff (all of whom were members of the seven communities) to participate in the consultation. As we walked through the proposed dialogue process, NFCS staff provided input (in response to the questions asked) and also suggested changes to wording and other aspects of the protocol. For example, the visual depiction of current services was reconfigured into the series of concentric circles found in Figure 2, during one of these NFCS staff focus groups. Thus, staff members also collaborated in the creation of this methodology, which in turn was useful for those individuals tasked with scheduling groups and interviews; it gave them a clearer sense of what they were asking of their fellow community members.

c) Emphasis on Anishinaabe Strengths: Early advice from an Elder to "acknowledge Anishinaabek traditional methods of caring for children" within our consultation process proved invaluable. It prompted the researchers to incorporate the medicine wheel as a visual and structural tool that would allow for a discussion of child-rearing practices from past/present/ future perspectives, as well as to acknowledge the impacts of colonialism on Anishinaabek childrearing, but within a greater context of Anishinaabek resistance and revitalization. Importantly, it allowed us to begin the consultation on a positive note of Indigenous strength (east), thus setting an optimistic tone for the conversation. Similarly, asking for input on Anishinaabek resilience and persistence in spite of European disruption (south) helped participants to perceive the continued strength of their ancestors (rather than becoming overwhelmed thinking about everything that has been lost due to colonialism). By the time we reached questions about present-day services (west), participants were usually engaged in the process and interested to see how present-day services and practices compared to those already discussed.

d) Empowering through Information: Using Figure 2, NORDIK researchers then provided an accessible overview of current services (west). In order to nurture participant engagement with the current system of services, and to naturalize the fact that its complexity is difficult for anyone not working within it to understand, the NORDIK researchers often prefaced this by stating that they themselves needed the diagram in order to keep all the various components straight. This step helped to clarify how the system works, and thus enabled a wide cross-section of community members to enter into a meaningful discussion critiquing the system's current strengths and weaknesses. In reviewing the current system, many people commented about how the system could be reformed, and also learned about the existence of certain services for the first time (e.g., Nog-da-win-da-min's self-esteem program for youth, entitled, "I'm proud to be me: Anishinaabe") that they asked questions about and expressed an interest in utilizing. By providing the tools to participate fully in this examination of a complicated child-care system, it showed participants that all people's opinions have value and are worthy of respect.

e) "Safe Space": NORDIK researchers acted as advocates for community members (not as representatives for Nog-da-win-da-min, nor with any other agenda). The NORDIK team's priority was simply to get an accurate understanding of community perspectives (however diverse they may be), and then relay this information to Nog-da-win-da-min and community leaders. The fact that the researchers were not affiliated with Nog-da-win-da-min or child welfare services helped to create a "safe space" in which participants felt they could speak openly, without fear of repercussions. 
f) Value of Engagement: After participating in the consultation process, a number of community members expressed how appreciative they were of the simple fact that anyone had considered it a priority to ask for their opinions and input before making a policy-level decision, particularly about an important issue like child welfare services in their own community. They spoke about how decisions are often made for them rather than with them, and that they had very much enjoyed the opportunity to participate and engage with others in these important issues. For their part, NORDIK researchers were careful to explain that they had been contracted by Nog-dawin-da-min to run the community consultation process, because the agency wanted individuals to feel free expressing anything (positive, negative, or neutral) about their agency without any fear of repercussions. Many participants seemed to agree that this was a good approach to take, and their impressions of the Nog-da-win-da-min agency began to improve. Nog-da-win-da-min took the vital first steps toward re-establishing a trusting and collaborative relationship with the seven First Nations, and several community members were strongly interested in continuing this conversation with the agency.

g) Separate draft reports belonging to each community: This effort respectfully acknowledged diversity from one community to another, and also provided for additional input into the consultation process. Furthermore, the ownership rights of each community were respected, in that the decision was left up to each community to decide what information should remain private versus being shared publically. The Nog-da-win-da-min board of directors is to be commended for respecting each diverse community's right to privacy and diversity. They approved the NORDIK researchers' request to submit one aggregated research report (following private draft-sharing consultations with each community), so that no community would have to worry about feeling "singled out" or compared (e.g., "These five communities support Nogda-win-da-min's application to become a mandated child protection agency and these two do not"). The final aggregated report was also useful in emphasizing that there were areas of clear consensus/commonalities across the seven communities in addition to diversity of opinion about Nog-da-win-da-min's present and future roles in child welfare issues.

Nog-da-win-da-min's initiative to re-establish a relationship with its member communities by means of a community-based consultation has led to some important knowledge about engaging in meaningful dialogue with First Nation communities, particularly around difficult issues such as child welfare. Using a strengths-based, Anishinaabek-centric approach in designing the process, using language which anchors the process in the communities' cultural and historical meanings and identities, and respecting the communities' diversities through the use of a variety of spaces and consultation techniques are all key components of a consultation which is engaging, inclusive, and conducive for sharing candid perspectives. In retrospect, one critique of this research design is that more could have been done to build local capacity in terms of community organization and group facilitation skills. Perhaps, as a next step, interested community members can form an ad hoc consultation committee and assist in mobilizing future community dialogues. NORDIK researchers were fortunate to have had this opportunity to work with and learn from the Nogda-win-da-min organization and the First Nation communities to which it delivers services, and look forward to the revitalized vision of minobimaadziwin for Anishinaabek children.

\section{References}

Airhihenbuwa CO. (1995). Health and culture beyond the western paradigm. Thousand Oaks, CA: Sage Publications.

(c) Heather Schmidt, Gayle Broad, Christine Sy, and Rosalind Johnston 


\section{A collaborative consultation with First Nations about children's well-being}

Bennett, M., \& Blackstock, C. (2002). Annotated bibliography and literature review on aspects of Aboriginal child welfare. Winnipeg: First Nations Child and Family Caring Society.

Boston, M., \& Broad, G. (2007). Community corner: A holistic approach to community empowerment in child and family services. Sault Ste. Marie, ON: Algoma University College.

Brubacher, M. (2006). Coming home: The story of Tikinagan Child and Family Services. Sioux Lookout, ON: Tikinagan Child and Family Services.

Chataway, C. J. (1998). Native Canada: The promise of research. History and Philosophy of Psychology Bulletin, 10(1), $17-20$.

Ermine, W., Sinclair, R., \& Jeffery, B. (2004). The Ethics of Research Involving Indigenous Peoples: Report of the Indigenous Peoples' Health Research Centre to the Interagency Advisory Panel on Research Ethics. Regina: Indigenous People's Health Research Centre.

Gaikezheyongai, S. (2002). The story of the seven fires. Owen Sound, ON: Ningwakwe Learning Press.

Jackson, T. (1993). A way of working: Participatory research and the Aboriginal movement in Canada. In P. Park, M. Brydon-Miller, B. Hall, \& T. Jackson, (Eds.), Voices of Change: Participatory Research in the United States and Canada, (pp. 47-64). Toronto: The Ontario Institute for Studies in Education Press.

Kirby, S.L., Greaves, L., \& Reid, C. (2006). Experience research social change: Methods beyond the mainstream (2nd edition). Peterborough, ON: Broadview Press.

Labonte, R., \& Robertson, A. (1996). Delivering the goods, showing our stuff: The case for a constructivist paradigm for health promotion research and practice. Health Education Quarterly, 23(4), 431-447.

Libesman, T. (2004). Child welfare approaches for Indigenous communities: International perspectives. Child Abuse Prevention Issues, 20, 1-39.

Mayan, M., (2009). The Essentials of Qualitative Inquiry. Walnut Creek, CA: LeftCoast Press.

Mihesuah, D. A. (1998). Introduction. In D. A. Mihesuah (Ed.), "Natives and Academics: Researching and Writing about American Indians," (pp. 1-22), Lincoln: University of Nebraska Press.

Okubo, D., \& Weidman, K. (2000). Engaging the community in core public health functions. National Civic Review, 89 (4): 309-326.

Schnarch, B. (2004). Ownership, control, access, and possession (OCAP) or self-determination applied to research: A critical analysis of contemporary First Nations research and some options for First Nations communities. Journal of Aboriginal Health, 80-95.

Smith, L. T. (1999). Decolonizing Methodologies: Research and Indigenous Peoples. New York: Zed Books.

Shank, G. (2002). Qualitative research: A personal skills approach (2nd ed). Upper Saddle River, NJ: Pearson Education Inc. 